\title{
Nicotine Acts on Cholinergic Signaling Mechanisms to Directly Modulate Choroid Plexus Function
}

\author{
DValeria Lallai, ${ }^{1}$ Nickolas Grimes, ${ }^{1}$ James P. Fowler, ${ }^{1}$ P. Adolfo Sequeira, ${ }^{2}$ Preston Cartagena, ${ }^{2}$ Agenor \\ Limon, ${ }^{2}$ Margaret Coutts, ${ }^{3}$ E Edwin S. Monuki, ${ }^{3}$ William Bunney, ${ }^{2}$ Angelo Demuro, ${ }^{1}$ and $\mathbb{C}^{\text {Christie D. }}$ \\ Fowler $^{1}$
}

https://doi.org/10.1523/ENEURO.0051-19.2019

${ }^{1}$ Department of Neurobiology and Behavior, University of California Irvine, Irvine, CA, 92697, ${ }^{2}$ Department of Psychiatry and Human Behavior, School of Medicine, University of California Irvine, Irvine, CA 92697, and

${ }^{3}$ Department of Pathology, School of Medicine, University of California Irvine, Irvine, CA, 92697

\begin{abstract}
Neuronal cholinergic circuits have been implicated in cognitive function and neurological disease, but the role of cholinergic signaling in other cellular populations within the brain has not been as fully defined. Here, we show that cholinergic signaling mechanisms are involved in mediating the function of the choroid plexus, the brain structure responsible for generating CSF and releasing various factors into the brain. The choroid plexus was found to express markers of endogenous cholinergic signaling, including multiple nicotinic acetylcholine receptor (nAChR) subtypes in a region-specific manner, and application of nicotine was found to induce cellular activation, as evidenced by calcium influx in primary tissue. During intravenous nicotine self-administration in male rats, nicotine increased expression of transthyretin, a protein selectively produced and released by the choroid plexus, and microRNA-204 (mir-204), a transcript found in high levels in the choroid plexus and CSF. Finally, human choroid plexus tissue from both sexes was found to exhibit similar nAChR, transthyretin and mir-204 expression profiles, supporting the translational relevance of the findings. Together, these studies demonstrate functionally active cholinergic signaling mechanisms in the choroid plexus, the resulting effects on transthyretin and mir-204 expression, and reveal the direct mechanism by which nicotine modulates function of this tissue.
\end{abstract}

Key words: choroid plexus; drug dependence; microRNA; nicotine; nicotinic acetylcholine receptors; transthyretin

\section{Significance Statement}

Tobacco/nicotine dependence is the largest preventable cause of disease and death worldwide. The current investigations establish the presence of cholinergic signaling mechanisms in the choroid plexus and demonstrate nicotine-mediated changes in transthyretin and microRNA-204 (mir-204) expression. These changes were attributed to nicotine's direct actions on nicotinic acetylcholine receptors (nAChRs) in the choroid plexus tissue. Therefore, these studies elucidate a previously unrecognized cholinergic neuroregulatory system, which may have relevant implications for disease states characterized by cholinergic dysfunction, such as Alzheimer's disease, as well as nicotine dependence.

\section{Introduction}

Cholinergic neuronal signaling has been shown to modulate various aspects of cognition, motivated behavior, and learning and memory function (Picciotto et al., 2012).
At the cellular level, acetylcholine activates nicotinic acetylcholine receptors (nAChRs) or muscarinic AChRs. Such receptor activation has been shown to modulate a variety of cellular signaling processes, including neuronal excit- 
ability, gene expression, presynaptic release of neurotransmitters, and synaptic plasticity (Gray et al., 1996; Grady et al., 2001; Parikh et al., 2007; Dani et al., 2011). In addition to normal physiological function, cholinergic signaling has been associated with several neuropsychiatric and neurodegenerative disorders, such as dementia, Alzheimer's disease, Parkinson's disease, and schizophrenia, in which a deficit in cholinergic function is proposed to underlie disease-specific symptomology (Whitehouse et al., 1982; Coyle et al., 1983; Bordia et al., 2007; Bohnen and Albin, 2011; Sarter et al., 2012). Pharmacological approaches targeting the cholinergic system have also been the focus of multiple drug development efforts in the clinical setting (Jorenby et al., 2006; McHardy et al., 2017), and nicotine, the main psychoactive substance in tobacco and e-cigarettes, directly acts on nAChRs to mediate various aspects of drug dependence (Picciotto et al., 1998; Fowler et al., 2011; Fowler and Kenny, 2014).

The choroid plexus is a structure comprised of epithelial cells, which is localized throughout the ventricular system of the brain. Historically, the main role of the choroid plexus was attributed to the production of CSF. However, more recent findings have begun to elucidate other functions. For instance, CSF released from the choroid plexus has been shown to regulate neurogenesis throughout the lifespan (Lehtinen and Walsh, 2011; Lehtinen et al., 2011) and to play a role in Alzheimer's disease pathology (Bateman et al., 2006; Krzyzanowska and Carro, 2012; Potter et al., 2013). The CSF-derived factors involved in these functions may include growth factors (e.g., Igf2, BDNF, and VEGF), proteins (e.g., transthyretin and apolipoprotein $\mathrm{J}$ ), and could also include extracellular vesicles containing various RNA species (Lehtinen et al., 2011; Krzyzanowska and Carro, 2012; Ochoa et al., 2015; Lee et al., 2016; Riancho et al., 2017; Derkow et al., 2018), although the full extent of factors released by the choroid plexus with relevance to disease pathology remains to be elucidated. The extensive basolateral infoldings of the choroid plexus afford significant surface area for the release and uptake of signaling factors, whereas tight gap junctions and transporters regulate passage of substances between the blood and CSF (Balusu et al., 2016). The rate of production of CSF is projected to allow for turnover of approximately four times per day in humans (Johanson et al., 2005), and thus, the levels of circulating factors can be continuously regulated to influence neural

wrote the paper; P.A.S., P.C., A.L., M.C., E.S.M., W.B., A.D., and C.D.F. contributed unpublished reagents/analytic tools.

This work was supported by the National Institutes of Health Grants DA032543 and DA039658 (to C.D.F.) and AG053988 (to A.D.).

Acknowledgements: We thank the Orange County Coroner's office and Ms. Kathleen Burke for technical assistance in obtaining the human brain tissue samples. We also thank the expert technical assistance provided by Dr. Vanessa Ochoa with aspects of the project.

Correspondence should be addressed to Christie D. Fowler at cdfowler@uci.edu

https://doi.org/10.1523/ENEURO.0051-19.2019

Copyright (C) 2019 Lallai et al.

This is an open-access article distributed under the terms of the Creative Commons Attribution 4.0 International license, which permits unrestricted use, distribution and reproduction in any medium provided that the original work is properly attributed. function. Choroid plexus epithelium is found throughout the ventricular locations, including the lateral, third and fourth ventricles. At each of these sites during development, the choroid plexus has been proposed to differ in structure and function (Johanson et al., 2005; Lun et al., 2015a). While nicotine has been shown to be localized in choroid plexus tissue in vitro (Spector and Goldberg, 1982), it has remained unknown as to whether nAChRs are expressed and/or functionally mediate signaling within the choroid plexus cells.

In the current studies, we sought to identify whether endogenous cholinergic signaling mechanisms are localized in choroid plexus epithelium. Initial evidence indicated that nicotine could act directly to mediate choroid plexus function, and thus, we assessed whether cholinergic cells and nAChR subunits are differentially expressed across ventricular locations. Thereafter, we examined whether chronic nicotine self-administration would lead to altered expression of mRNA and miRNA in a region-specific manner. Specifically, we focused our investigations on the choroid plexus-specific protein, transthyretin, which has been found to be increased in the CSF during nicotine exposure, and microRNA-204 (mir204), which is expressed in high density in the choroid plexus (Li et al., 2000, 2016; Oberwinkler et al., 2005). Primary choroid plexus cell culture was used to provide further evidence of nicotine's direct impact on cellular activation with calcium imaging. Finally, nAChR subunits, transthyretin and mir-204 expression were examined in tissue from human subjects, thus providing translational relevance for the potential impact of these findings in humans.

\section{Materials and Methods}

\section{Animals}

Adult, male Wistar rats (RRID:RGD_13508588; $n=78$ ) weighing 275-300 g were obtained from Charles River Laboratories and housed two to three per cage. ChATIRES-Cre (B6;129S6-Chattm2(cre)Lowl/J; Stock 006410; RRID:IMSR_JAX:006410) and ROSA ${ }^{26 S o r}$-tdTomato reporter (B6.Cg-Gt(ROSA)26Sortm14(CAG-tdTomato)Hze/J; Stock 007914; RRID:IMSR_JAX:007914) mice were obtained from The Jackson Laboratory and bred within our colony as hemizygous mating pairs. Both founder lines were backcrossed on a C57BL/6J background (RRID: IMSR_JAX:000664) for at least 10 generations before the current breeding cross. Pups were weaned at $21 \mathrm{~d}$ of age and housed three to five per cage. Adult male hemizygous ChAT-IRES-Cre::Rosa-TdTomato mice $(n=5)$ were used to characterize the presence of cholinergic cells within the choroid plexus. Rats and mice were maintained in an environmentally controlled vivarium on a $12 / 12 \mathrm{~h}$ light/ dark cycle, and food and water were provided ad libitum. All experimental subjects were randomly assigned to treatment conditions. However, during self-administration, rats were mildly food restricted to $85-90 \%$ of their free-feeding body weight, while water was maintained ad libitum. All procedures were conducted in strict accordance with ethical regulations outlined in the National Institutes of Health Guide for the Care and Use of Labo- 
ratory Animals and were approved by the Institutional Animal Care and Use Committee at the University of California, Irvine.

\section{Mouse genotyping}

At $21 \mathrm{~d}$ of age, mouse pups were weaned and their tails were clipped for genetic analysis. Subjects were genotyped by PCR with the following primers: ChAT-IRES-Cre: 5'-GTT TGC AGA AGC GGT GGG-3' (wild type forward), 5'-CCT TCT ATC GCC TTC TTG ACG-3' (mutant forward), 5'-AGA TAG ATA ATG AGA GGC TC-3' (common reverse); Rosa-TdTomato 5'-AAG GGA GCT GCA GTG GAG TA-3' (wild type forward), 5'-CCG AAA ATC TGT GGG AAG TC-3' (wild type reverse), 5'-CTG TTC CTG TAC GGC ATG G-3' (mutant forward), 5'-GGC ATT AAA GCA GCG TAT CC-3' (mutant reverse).

\section{Drugs}

Mecamylamine hydrochloride (Tocris Bioscence) was diluted in $0.9 \%$ sterile saline and injected subcutaneously at a dose of $2 \mathrm{mg} / \mathrm{kg}$. (-)-Nicotine hydrogen tartrate salt (MP Biomedicals) was dissolved in $0.9 \%$ sterile saline $(\mathrm{pH}$ 7.4), and doses of nicotine refer to the free-base form. Ketamine (KetaVed, Patterson Veterinary) and xylazine (AnaSed, Patterson Veterinary) were diluted in sterile saline and simultaneously injected intraperitoneally at a dose of 100 and $10 \mathrm{mg} / \mathrm{kg}$, respectively, for mouse perfusions. Isoflurane (IsoFlo, Abbott Laboratories) was administered as a $1-3 \%$ mixture with oxygen via inhalation.

\section{Experimental design}

Mouse perfusion and tissue processing

Adult, hemizygous ChAT-IRES-Cre::Rosa-TdTomato mice were anesthetized with ketamine/xylazine and perfused through the ascending aorta with $0.9 \%$ saline, followed by $4 \%$ paraformaldehyde in $0.1 \mathrm{M}$ PBS $(\mathrm{pH} 7.4)$. Brains were harvested, postfixed for $2 \mathrm{~h}$ in $4 \%$ paraformaldehyde, and then stored in $30 \%$ sucrose in PBS. After at least $72 \mathrm{~h}$, brains were cut into $30-\mu \mathrm{m}$ coronal sections on a cryostat, and floating sections were stored in $0.1 \mathrm{M}$ PBS with $0.01 \%$ sodium azide at $4^{\circ} \mathrm{C}$. To visualize TdTomato fluorescence, sections were directly mounted onto slides and coverslipped with vectashield.

\section{Primary choroid plexus epithelial cell culture and $\mathrm{Ca}^{2+}$ fluorescence imaging}

Primary cultures of choroid plexus epithelial cells were prepared from dissected tissue of naïve, adult Wistar male rats $(n=6)$. Directly after decapitation, choroid plexus tissue was separately isolated from the third ventricle (3V) of the brain and then pooled across subjects to derive sufficient cell quantity for primary culture. Thereafter, cells were treated with collagenase Type II and TrypLE Express (Gibco). To obtain a monolayer culture, cells were plated on a modified recording chamber consisting of a silicon O-ring (Sealing Devices Incorporation), mounted on a cover glass (Warner Instruments), and treated with polyD-lysine coated to improve cells adhesion. Cultures achieved confluency by $2-3 \mathrm{~d}$ at $\cong 10,000 \mathrm{cells} / \mathrm{cm}^{2}$ in DMEM with $10 \%$ FBS exosome-depleted serum and $1 \times$ pen-strep solution (Gibco). Culture media was changed every 2-3 d, unless otherwise specified. Cell culture plates were maintained in a humidified $37^{\circ} \mathrm{C}$ incubator containing $5 \% \mathrm{CO}_{2}$. The $\mathrm{Ca}^{2+}$-sensitive dye Cal-520 (AAT Bioquest) was reconstituted with DMSO containing $20 \%$ pluronic F-127 (Invitrogen). Before imaging, culture medium was replaced with a $\mathrm{Ca}^{2+}$-containing HEPESbuffered salt solution composed of $135 \mathrm{mM} \mathrm{NaCl}, 5.4 \mathrm{mM}$ $\mathrm{KCl}, 2 \mathrm{mM} \mathrm{CaCl}$, $1 \mathrm{mM} \mathrm{MgCl}_{2}, 10 \mathrm{mM} \mathrm{HEPES}$, and 10 $\mathrm{mM}$ glucose $(\mathrm{pH}$ 7.4). Cells were then incubated with 5 $\mu \mathrm{M}$ Cal-520 (AM esters) for $\sim 50 \mathrm{~min}$ at room temperature. Cells were washed afterward for at least $30 \mathrm{~min}$, and then nicotine was applied by pipetting a fixed aliquot $(30 \mu \mathrm{l})$ of the diluted stock solution into the recording chamber (470- $\mu$ l volume) directly above the microscope objective. The EC50 for nicotine/ACh for the different neuronal nAChRs subtypes range from $\sim 2$ to $30 \mu \mathrm{M}$ (Demuro et al., 2001; Demuro and Parker, 2005). As our rationale was to generate a robust response by activating all the possible nAChRs subtypes present in the cells, we performed experiments using $30 \mu \mathrm{M}$ nicotine. The imaging system consisted of an inverted microscope (Olympus IX 71) equipped with a $60 \times$ total internal reflection fluorescence (TIRF) oil immersion objective (NA 1.45) as previously described (Demuro and Parker, 2005). Fluorescence excitation was induced with a 488-nm laser from a laser combiner (L4C OXXIUS S.A.). Emitted fluorescence (510 $\mathrm{nm})$ was detected with a green bandpass $(520 \pm 20 \mathrm{~nm})$ emission filter to record $\mathrm{Ca}^{2+}$ fluorescence signals generated by Cal-520. Images were captured using a sCMOS camera (Andor Zyla 4.2) providing a final magnification of $200 \mathrm{~nm}$ per pixel. Image acquisition was controlled by MicroManager open source microscopy software (https:// micro-manager.org/) connected to the computer trough a USB2 port. The camera was set to acquire from a central region of interest of $256 \times 256$ pixels, corresponding to $\sim 50 \times 50 \mu \mathrm{m}$ of the specimen. Time-lapse images (frame rate $50 \mathrm{fps}$ ) were captured using Micromanager software. Images were processed using MetaMorph software package (Universal Imaging) and measurements were exported to Microcal Origin2017 (OriginLab) for analysis and graphing. Averaged fluorescence intensities were measured from regions of interest and expressed as a pseudo ratio $(\Delta F / F o)$ of the change in fluorescence $(\Delta F)$ divided by the resting fluorescence before treatment $(F o)$.

\section{Intravenous nicotine and saline self-administration}

Before catheter implantation, rats were food restricted to $85-90 \%$ of their free-feeding body weight and trained to press an active lever in an operant chamber (Med Associates) for food pellets ( $45 \mathrm{mg}$, 5TUM, TestDiet). Rats were trained up to a fixed-ratio 5 time out $20 \mathrm{~s}$ (FR5TO20) schedule of reinforcement during 1-h sessions. Selfadministration sessions were performed using two retractable levers (one active, one inactive) that extend $1 \mathrm{~cm}$ into the chamber. Completion of the response criteria on the active lever resulted in delivery of the food pellet. Responses to the inactive lever resulted in no scheduled consequence. After achieving food-training criteria of $>60$ pellets per session for three consecutive days, rats were implanted with the intravenous catheters. For intravenous surgery, rats were placed under anesthesia with an isoflurane $(1-3 \%)$ /oxygen mixture and surgerized as de- 
scribed previously (Fowler et al., 2011). Catheters were flushed daily via the port on the rat's dorsal region with heparin diluted in physiologic sterile saline solution. After $>48 \mathrm{~h}$ of postsurgical recovery, rats were food restricted as above and permitted to respond for food reinforcement under the FR5TO20 schedule. Subjects were randomly assigned into either the nicotine or saline condition (total $n=44$ nicotine; $n=28$ saline). After reinstating food responding across three sessions, rats in the nicotine group were then permitted access to the $0.03 \mathrm{mg} \mathrm{kg}^{-1}$ training dose of nicotine for seven sessions and then transitioned to a higher dose of nicotine $\left(0.12 \mathrm{mg} \mathrm{kg}^{-1}\right)$, whereas the saline control were maintained on saline. To probe for the involvement of $\mathrm{nAChR}$ signaling in mediating changes in transthyretin expression, $20 \mathrm{~min}$ before the last session, rats were injected with mecamylamine (2 $\mathrm{mg} / \mathrm{kg}$, s.c.) or saline (s.c.). The specific sequence of testing was as follows: food training $(5+$ sessions until criterion is achieved) $\rightarrow$ intravenous surgery and recovery $\rightarrow$ reinstated food training (two to three sessions) $\rightarrow 0.03$ $\mathrm{mg} / \mathrm{kg} /$ infusion nicotine (7 sessions) $\rightarrow 0.12 \mathrm{mg} \mathrm{kg}^{-1}$ per infusion nicotine (1 session; for the mecamylamine study, vehicle/mecamylamine administered before this session). We designed the experiment with the transition to this moderately-high dose to have the rats actively titrate their behavior to obtain the desired amount of nicotine. In a prior study (Fowler et al., 2011), we found that rats will titrate their nicotine intake to a similar level across the dose range of $0.06-0.18 \mathrm{mg} \mathrm{kg}^{-1}$ per infusion, and given the localization of the dorsal $3 \mathrm{~V}$ (d3V) choroid plexus in juxtaposition to the medial habenula, which is preferentially activated at higher nicotine doses (Fowler et al., 2011; Frahm et al., 2011), we hypothesized that this dose may be particularly relevant to reveal functionally significant processes potentially mitigating drug intake. Subjects in the saline self-administration control group went through the identical procedure as noted above, but saline was provided for intravenous self-administration in the absence of nicotine. Subjects were killed after the final self-administration session, and saline and mecamylamine-injected subjects were pseudo-yoked to the number of infusions of the nicotine subjects to normalize for the amount of total saline intake between groups. All subjects were within a proximate range for the amount of saline infused via the intravenous catheter.

\section{Choroid plexus tissue dissection}

Rats were placed under isoflurane anesthesia and decapitated. The whole brain was removed and immediately transferred to a Petri dish and cut along the coronal plane at the levels of the septum and raphe nucleus with a straight edge blade. The dorsal brain portion was transferred to a Petri dish and superglued to the bottom of the dish, with the cerebellum and brainstem facing upward. The dish was filled with ice cold 0.1 M PBS and placed under a dissecting microscope. Thereafter, the cerebellum was gently separated from the cerebrum tissue with forceps, allowing the fourth ventricle to be exposed. The choroid plexus was gently removed and verified to not contain any attached brain tissue or dura matter via microscopic inspection. For the lateral and third choroid plexus dissections, the middle portion of the brain was superglued on the ventral surface to a Petri dish, and the dish was filled with ice cold PBS and placed under the dissecting microscope. A straight edge blade was used to cut the corpus callosum and hippocampus along the longitudinal fissure. Thereafter, the cortex and hippocampus were gently pulled to either lateral side with forceps to expose the $\mathrm{d} 3 \mathrm{~V}$ choroid plexus, which was removed and visually inspected under the microscope to ensure only the presence of the choroid plexus tissue (no attached brain tissue). Next, to obtain the lateral ventricle choroid plexus, the hippocampus was dislodged on each side to reveal the lateral ventricles, and the choroid plexus was then removed from this location. Further, the hippocampus and habenula were visually inspected under the microscope to ensure that they were fully intact, and these tissues were then biobanked. Samples were flash frozen in a collection tube and coded with unique numbers so that experimenters processing the tissue were blinded to the experimental condition. Samples were assigned in a random within group manner into analyses for RT-PCR by a second experimenter while maintaining blinding for the experimenter processing the tissue, and each sample was analyzed for multiple PCR assays based on the amount of RNA derived from each subject. Postmortem human choroid plexus samples were immediately frozen on dry ice at the time of dissection and placed in coded collection containers. All tissue was stored at $-80^{\circ} \mathrm{C}$.

\section{Human brain tissue}

Postmortem human choroid plexus tissue was provided by the University of California Irvin Brain Bank through a collaboration. Subjects ranged in age from 49 to 59, consisted of two men and one woman, and were classified as "control" subjects (although history of multi-drug use was noted in one of the men and the woman; the woman was also diagnosed with obesity). Experimenters did not receive access to personal identifying information regarding the human subjects. Brain tissue collection was conducted in accordance with the University of California Irvin Brain Bank standard operating procedure, relevant ethical regulations, and approved human Institutional Review Board protocol at University of California Irvine. Informed consent was provided by the legal next-of-kin with a University of California Irvine institutional approved consent form.

\section{RNA analysis}

RNA was extracted from homogenized tissue with TRIzol reagent (Ambion Life Technologies) via the manufacturer's protocol. The quality of the RNA was determined by a NanoDrop 2000 spectrophotometer (ThermoScientific). For each sample, $100 \mathrm{ng}$ of total RNA was reverse transcribed into cDNA with the iScript cDNA synthesis kit (Bio-Rad Laboratories). RT-qPCR was performed for nAChR subunits, transthyretin (TTR), mir-204 and the housekeeping genes, $\beta$-actin (ACTB) or U6 (RNU6). TaqMan Universal Master Mix II with real-time PCR gene expression assays for CHRNA3, CHRNA5, CHRNA7, CHRNA4, CHRNA6, CHRNA9, CHRNA10, CHRNB4, CHRNB2, CHRNB3, TTR, mir-204, and ACTB (control) or 


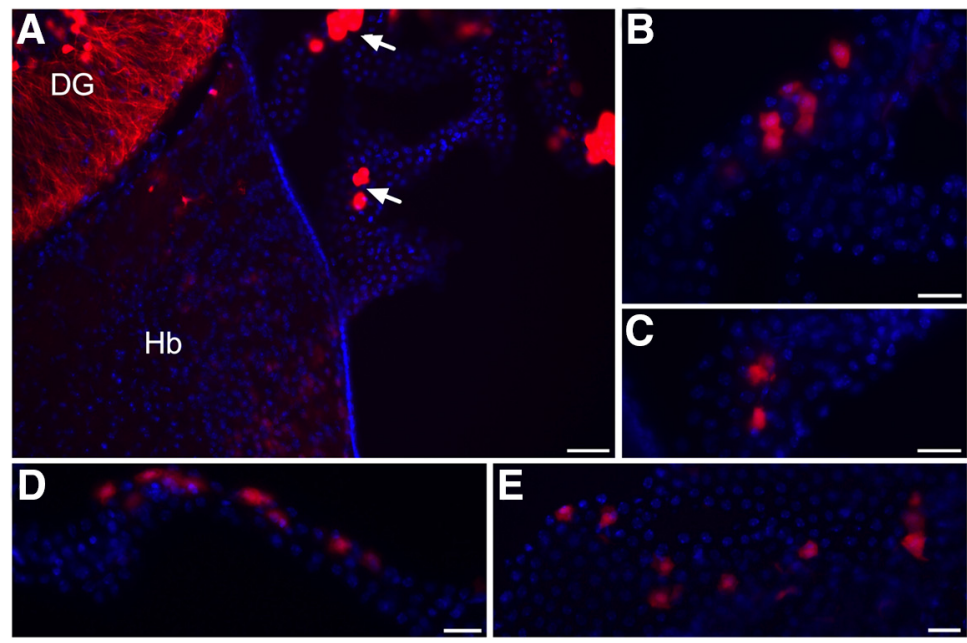

Figure 1. Cholinergic choroid plexus epithelial cells. A, Visualization of cholinergic cells in transgenic mice expressing td-Tomato fluorescence under the ChAT promotor. Cholinergic cells (red) are found within the dentate gyrus of the hippocampus (DG), habenula $(\mathrm{Hb})$, and the choroid plexus of the d3V (arrows). ChAT: red; DAPI nuclei: blue. Scale bar $=50 \mu \mathrm{m}$. $\boldsymbol{B}$, Higher magnification of the choroid plexus epithelium from the top arrow in panel $\boldsymbol{A}$ illustrates scattered expression pattern with groups of adjacent cholinergicpositive cells. Scale bar $=25 \mu \mathrm{m}$. $\boldsymbol{C}$, Higher magnification image of the epithelium from the bottom arrow in panel $\boldsymbol{A}$. Scale bar $=25$ $\mu \mathrm{m}$. $\boldsymbol{D}$, Cholinergic-positive cells were also identified in the lateral ventricle with a similar expression pattern. Scale bar $=25 \mu \mathrm{m}$. $\boldsymbol{E}$ In the fourth ventricle choroid plexus, similar ChAT expression was observed in a subset of epithelial cells. Scale bar $=25 \mu \mathrm{m}$.

microRNA assay for miR-204 and RNU6 (control) were used according to manufactures parameters (Applied Biosystems). Samples were tested in duplicate or triplicate (depending on quantity of RNA available per dissection) and quantified with a CFX96 RT-qPCR system (Bio-Rad). Samples with $\mathrm{Ct}$ values $>35$ cycles were considered outside of the range of inclusion as predetermined criteria, and thus, these samples were determined to exhibit no RNA expression in the tissue of interest. Normalized gene expression $\left(2^{\Delta \mathrm{Ct}}\right)$ was calculated with the equation $2^{\wedge(\beta-}$ actin $\mathrm{Ct}$ - target mRNA Ct). For $\mathrm{nAChR}$ subunit genes, normalized values were multiplied by 10,000 to represent data as whole numbers, and for the miRNA gene expression assay, normalized values were multiplied by 1000 . For the microRNA assay, normalized mi-204 expression $\left(2^{\Delta \mathrm{Ct}}\right)$ was calculated with the equation $2^{\wedge}(\mathrm{U} 6 \mathrm{Ct}-$ target miRNA $\mathrm{Ct})$. After samples were processed, group assignment was revealed to permit comparisons of the data.

\section{Statistical analysis}

Statistical details of experiments can be found in the results and figure legends. Data were analyzed by $t$ test (two-sided, unpaired) or one-way ANOVA, followed by a Bonferroni post hoc test with correction for multiple comparisons (GraphPad Prism 6), as appropriate. The criterion for significance was set at $p<0.05$.

\section{Results}

\section{Cholinergic signaling mechanisms are localized in epithelial cells of the choroid plexus}

In ChAT-IRES-Cre::ROSA ${ }^{26 S o r}$-tdTomato mice, we identified choroid plexus epithelial cells that express ChAT, the conventional marker used to identify cholinergic cells in the brain. Other brain region specific cholinergic expression in these mice was representative of that described in the literature and as previously characterized in this mouse line (GENSAT, 2019; Chen et al., 2018), for instance as shown in hippocampus and habenula (Fig. 1A). Within the d3V, scattered cholinergic cells were found throughout the choroid plexus (Fig. $1 A-C$ ). Further, choroid plexus epithelial cells in the lateral ventricle (Fig. 1D) and fourth ventricle (Fig. 1E) also exhibited a similar expression profile with a subset of cholinergic-positive cells.

\section{Nicotine directly activates a subset of epithelial cells, inducing calcium influx}

To determine whether nicotine functionally activates the choroid plexus cells, as opposed to just being transported through the tissue (Spector and Goldberg, 1982), we performed TIRF $\mathrm{Ca}^{2+}$ imaging experiments to monitor $\mathrm{Ca}^{2+}$ influx into the cytosol during nicotine-mediated activation of $n A C h R$ channels in the plasma membrane. Application of nicotine $(30 \mu \mathrm{M})$ into the bath solution triggered a time-dependent rise in $\mathrm{Ca}^{2+}$ fluorescence signal within a few seconds after administration (Fig. $2 A, B$ ). The emitted fluorescence signal slowly decayed during the 30-s recording window, which is in agreement with the $\mathrm{nAChR}$ kinetics for receptor activation followed by desensitization. Of note, a statistically significant robust response to nicotine was only found in a subset $(18.4 \%)$ of the cells imaged (two-sided, unpaired $t$ test, $t_{(47)}=7.79, p<$ $0.0001, R^{2}=56$; Fig. $2 C$ ). The "nonresponder" cells did exhibit localized, low-intensity spontaneous intracellular $\mathrm{Ca}^{2+}$ signaling in each imaged field during the recording period, verifying that all the cells were sufficiently loaded with the calcium indicator Cal-520 (Fig. 2). Finally, cultured cells were tested with $100 \mathrm{mM}$ ionomycin to further validate loading of the Cal-520 dye, and all visualized cells responded with a high fluorescence signal (data not shown), verifying the dye presence and cellular functionality potential. Of further note, the partial permeability to $\mathrm{Ca}^{2+}$ for $\mathrm{nAChRs}$ subtypes ranges from 0.8 to $4 \mathrm{pS}$. This relatively 
A
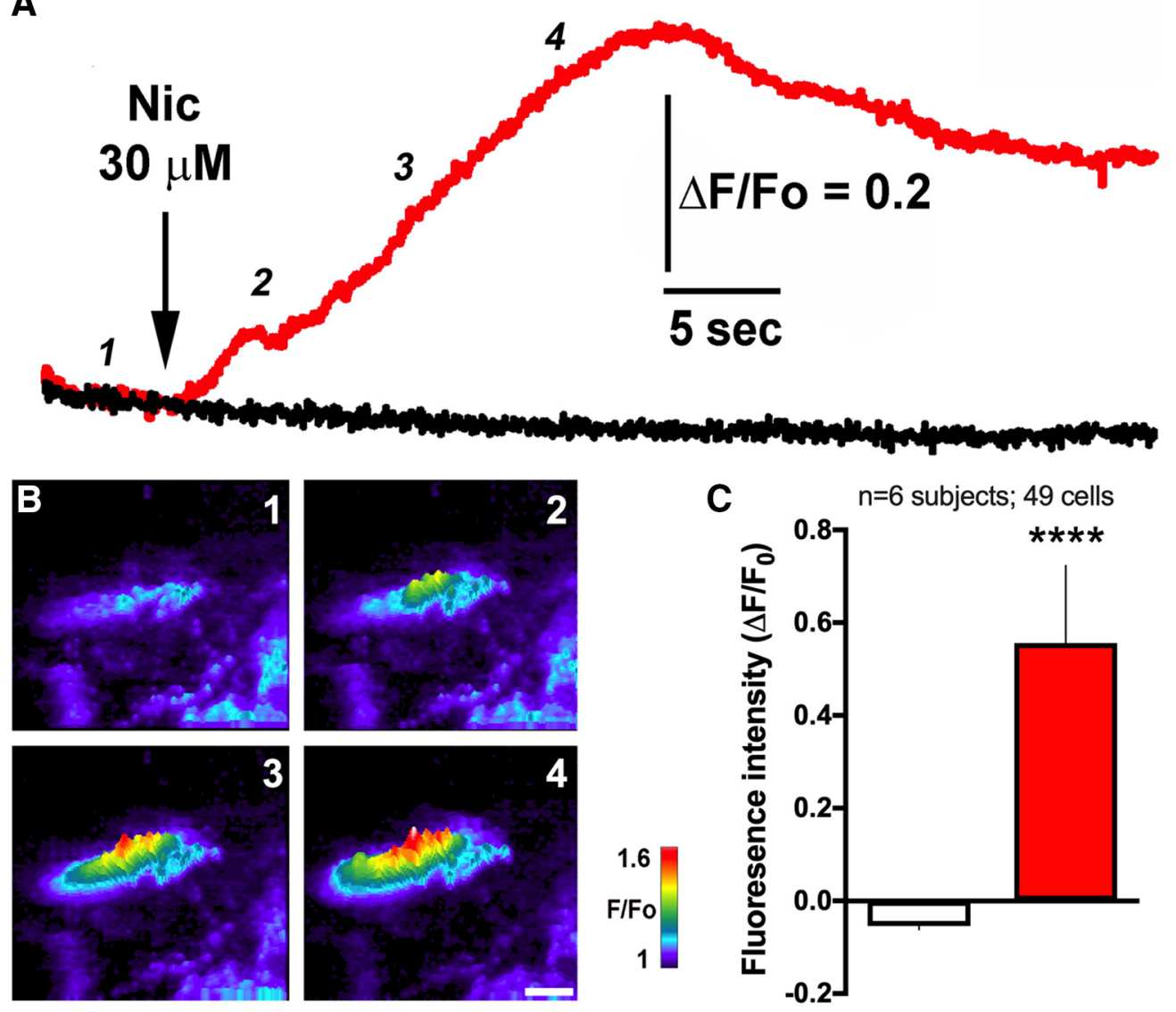

Figure 2. Nicotine activates calcium signaling in choroid plexus epithelial cells in vitro. $\boldsymbol{A}$, Time course of $\mathrm{Ca}^{2+}$-dependent fluorescence signal recorded from responding (red) and nonresponding (black) cells following application of $30 \mu \mathrm{M}$ nicotine. Traces represent average intensity from nine responsive (red) and 40 nonresponsive (black) primary choroid plexus epithelial cells in vitro. Primary choroid plexus obtained from $n=6$ rats (five cell culture plates analyzed, resulting in 49 cells quantified). $\boldsymbol{B}$, Representative images of a responsive cell (center) and nonresponsive cells (bottom right) captured at the time points 1-4 as indicated in $\boldsymbol{A}$. Increasing cytosolic free $\mathrm{Ca}^{2+}$ is represented by warmer colors (as depicted with the color bar) and increasing height of each pixel. Scale bar $=20 \mu \mathrm{m}$. C. Average fluorescence signals measured at the peak of each recording obtained during 11 separated trials; $* * * * p<0.0001$. Data represent mean \pm SEM. Central tendency (mean) and variation (SEM) values for each are as follows: nonresponsive, $-0.054 \pm 0.008$ and responsive, $0.556 \pm 0.167$.

small conductance allows a large flux of $\mathrm{Ca}^{2+}$ into the cells which, by binding to the $\mathrm{Ca}^{2+}$-sensitive dye, is amplified to become a robust fluorescence signal. As such, in the TIRF technique, it is now possible to monitor $\mathrm{Ca}^{2+}$ flux trough the opening of a single nAChRs (Demuro and Parker, 2005, 2006). Although we cannot exclude the possibility of other components contributing to the cytosolic $\mathrm{Ca}^{2+}$ rise, such as CICR through RyRs or calcium influx through store-operated $\mathrm{Ca}^{2+}$ channels, the temporal evolution and the time to response obtained in these experiments strongly suggest that the fluorescence signal is due to the opening nAChRs in the plasma membrane of these cells.

\section{Multiple nAChR subunits exhibit region-specific expression patterns in the choroid plexus}

$A$ variety of $n A C h R$ subunits have been documented within the brain, and functional pentameric nAChR subtypes include varying combinations of $\alpha 2-\alpha 10$ and/or $\beta 2-\beta 4$ subunits (Fowler et al., 2008). In the current studies, we systematically examined the expression of $n A C h R$ subunit mRNA in the three choroid plexus locations in rats. Tissues were discretely dissected from each ventri- cle location (e.g., as shown for the d3V; Fig. 3A). Interestingly, differential expression profiles were discovered based on the ventricular localization. In the lateral ventricle choroid plexus (Fig. 3B), $\alpha 4, \alpha 5, \beta 2, \beta 3$, and $\beta 4 \mathrm{nAChR}$ subunits were found. In the fourth ventricle choroid plexus (Fig. 3C), $\alpha 4$ and $\beta 2 \mathrm{nAChR}$ subunits were expressed. Finally, $\alpha 4, \alpha 7, \beta 2$, and $\beta 3 \mathrm{nAChR}$ subunits were identified in the $\mathrm{d} 3 \mathrm{~V}$ choroid plexus (Fig. $3 D$ ). Based on the literature for nAChR subunit stoichiometry, multiple functional receptor subtypes would be predicted across ventricular locations, as illustrated in the figure insets (Fig. $3 B-D$ ).

The $\alpha 4$ and $\beta 2$ nAChR subtypes are differentially expressed across ventricular sites and nicotine selfadministration does not consistently alter subunit expression

Given that $\alpha 4$ and $\beta 2$ were common to all locations, we next examined whether the level of expression significantly varied between the sites. For the $\alpha 4$ nAChR subunit, statistically significant differences in expression were found between the ventricular locations (one-way ANOVA, $F_{(2,40)}=13.69, p<0.0001, R^{2}=0.41$; Fig. $4 A$ ). 

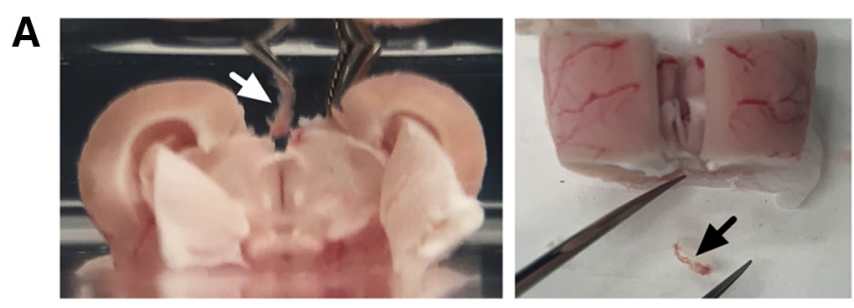

B

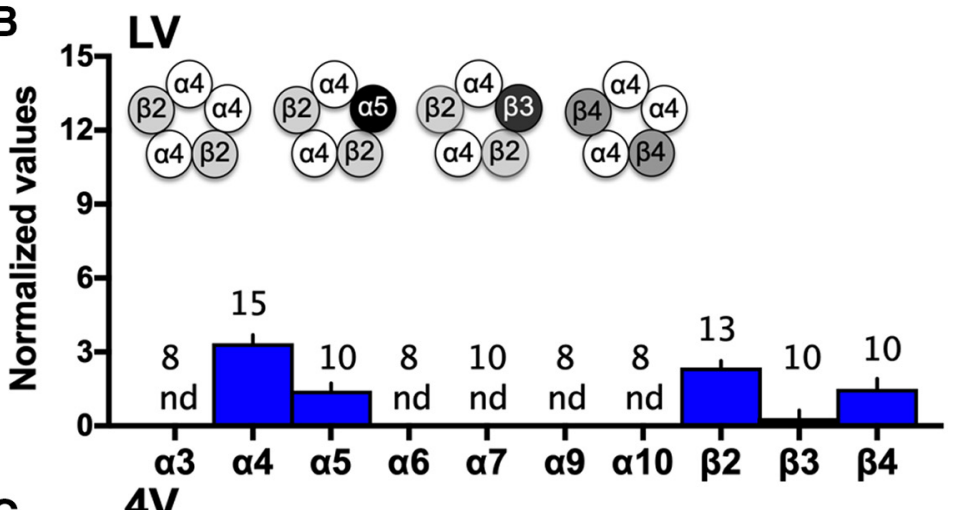

C

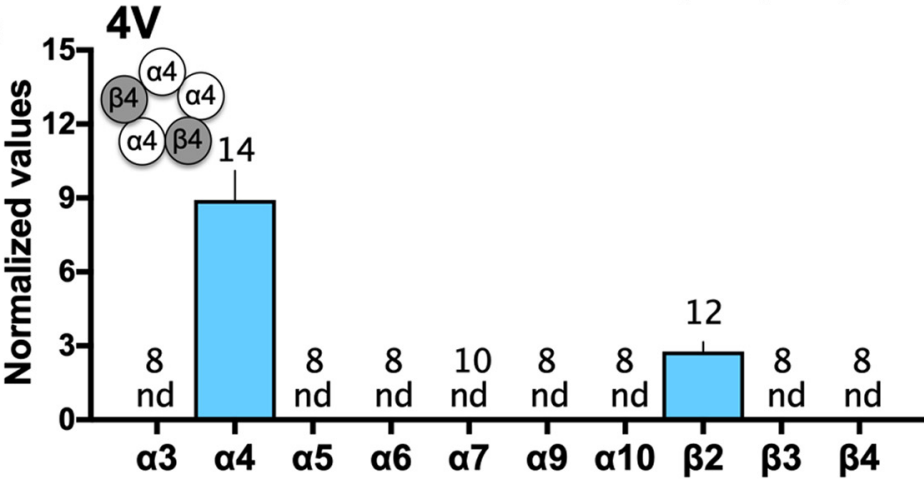

D

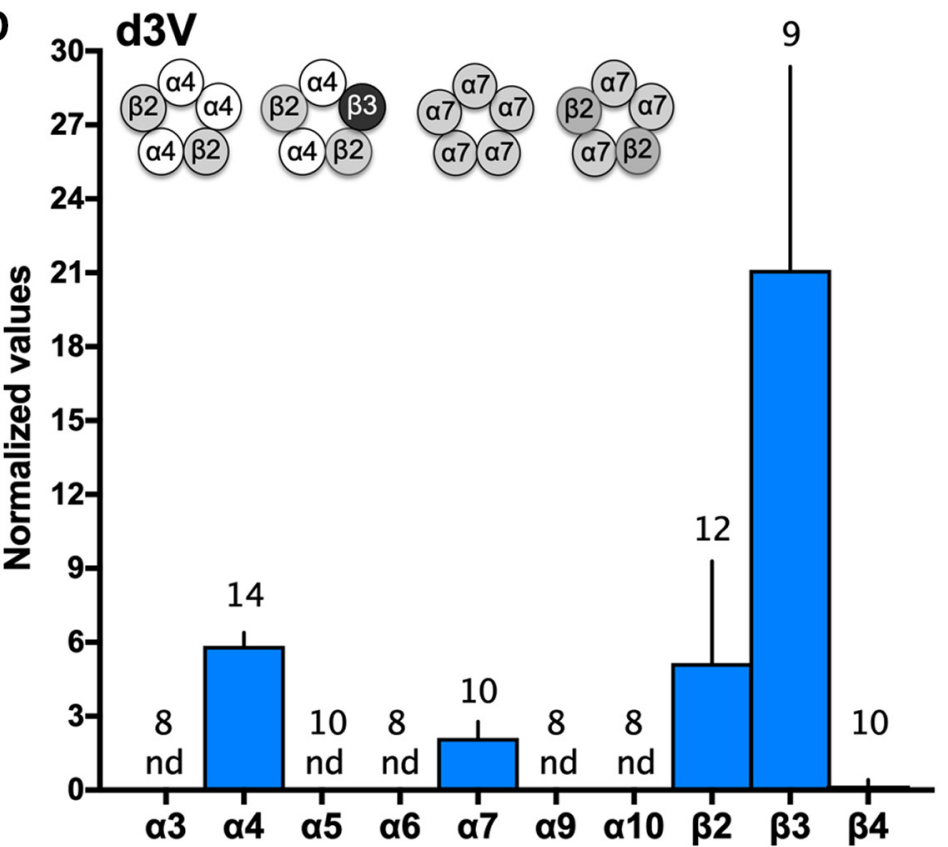

Figure 3. nAChR subunit expression in choroid plexus derived from the lateral, fourth, and d3Vs. Choroid plexus was discretely dissected from the ventricles of the brain. $\boldsymbol{A}$, The outer layer of cortex and hippocampus were gently separated from the midline to allow for visualization and removal of the d3V choroid plexus with visualization via dissection microscope (left image with white arrow), and following removal, the choroid plexus was clearly visualized as completely separate from brain tissue (right image with black arrow). Similar dissections were conducted with microscopic visualization and verification for the lateral and fourth ventricle locations. 
continued

$\boldsymbol{B}-\boldsymbol{D}$, The expression of $\mathrm{nAChR}$ subunits was examined in choroid plexus tissue from rats $(n=8-15 /$ group, specific number per group denoted on each bar). $\boldsymbol{B}$, In the lateral ventricle (LV), mRNA expression was found for the $\alpha 4$ (Chrna4), $\alpha 5$ (Chrna5), $\beta 2$ (Chrnb2), $\beta 3$ (Chrnb3), and $\beta 4$ (Chrnb4) nAChR subunits. Putative nAChR subtype schematics are graphically illustrated (insert). Statistical data are as follows [central tendency (mean) \pm variation (SEM), lower $95 \%$ confidence interval, upper 95\% confidence interval]: $\alpha 4: 3.35 \pm$ $0.34,2.61,4.09 ; \alpha 5: 1.44 \pm 0.29,0.77,2.10 ; \beta 2: 2.37 \pm 0.28,1.77,2.97 ; \beta 3: 0.32 \pm 0.32,0,1.03 ;$ and $\beta 4: 1.50 \pm 0.42,0.56,2.45$. C, In the fourth ventricle (4V), only $\alpha 4$ (Chrna4) and $\beta 2$ (Chrnb2) mRNAs were detected, and thus, the $\alpha 4 \beta 2$ nAChR subtype may be present (schematic insert). Statistical data are (mean \pm SEM, lower $\mathrm{Cl}$, upper $\mathrm{Cl}$ ): $\alpha 4: 8.93 \pm 1.18,6.38,11.47$ and $\beta 2: 2.77 \pm 0.38$, 1.93, 3.61. $\boldsymbol{D}$, In the d3V, subunit expression consisted of $\alpha 4$ (Chrna4), $\alpha 7$ (Chrna7), $\beta 2$ (Chrnb2), and $\beta 3$ (Chrnb3), which allows for four different putative nAChR subtypes (schematic insert). Statistical data are (mean \pm SEM, lower $\mathrm{Cl}, \mathrm{upper} \mathrm{Cl}$ ): $\alpha 4: 5.86 \pm 0.53$, $4.71,7.01 ; \alpha 7: 2.12 \pm 0.67,0.61,3.62 ; \beta 2: 5.16 \pm 1.19,2.53,7.79 ;$ and $\beta: 21.12 \pm 8.25,2.09,40.14$. For each nAChR gene above, expression data were normalized to expression of $\beta$-actin as the endogenous control. nd $=$ not detected based on the predetermined RT-qPCR criteria (Ct value $>35$ ). Data represent mean normalized values \pm SEM.

Post hoc analyses revealed increased $\alpha 4 \mathrm{nAChR}$ subunit mRNA expression in the fourth ventricle compared to the lateral and $3 \mathrm{~V}$. For the $\beta 2 \mathrm{nAChR}$ subunit, significant differences were again found among the groups (one-way ANOVA, $F_{(2,34)}=4.30, p=0.0217, R^{2}=0.20$; Fig. $4 B$ ), with post hoc analyses revealing significantly higher $\beta 2$ subunit mRNA expression in the $3 \mathrm{~V}$ choroid plexus as compared to the lateral.

In prior studies, chronic nicotine exposure has been found to increase radiotracer agonist binding for nAChRs in human smokers and rodent models (Benwell et al., 1988; Marks et al., 1992; Breese et al., 1997), suggesting a functional upregulation of receptors. Thus, given the differences found in the expression pattern of $\alpha 4$ and $\beta 2$ nAChR subunits across ventricular choroid plexus sites, we next sought to examine whether chronic nicotine intake would alter the mRNA expression of these subunits. Rats were behaviorally tested in the intravenous nicotine self-administration protocol to obtain tissue for analysis (Fig. 5A,B), and saline self-administration subjects were pseudo-yoked to allow for similar levels of saline intake between groups. When comparing tissue from saline versus nicotine self-administering rats, statistically significant differences were not found for the $\alpha 4$ nAChR subunit in the choroid plexus across locations, including the lateral ventricle (two-sided, unpaired $t$ test, $t_{(14)}=1.11, p=0.29$, $R^{2}=0.08$; Fig. $4 C$ ), fourth ventricle (two-sided, unpaired $t$ test, $t_{(14)}=0.47, p=0.64, R^{2}=0.02$; Fig. $4 E$ ), and d3V (two-sided, unpaired $t$ test, $t_{(14)}=0.71, p=0.49, R^{2}=$ 0.03 ; Fig. $4 G$ ). For the $\beta 2 \mathrm{nAChR}$ subunit, significant differences between groups were also not found in the lateral ventricle site (two-sided, unpaired $t$ test, $t_{(14)}=$ $0.47, p=0.47, R^{2}=0.04$; Fig. $4 D$ ) and d3V sites (twosided, unpaired $t$ test, $t_{(14)}=0.40, p=0.70, R^{2}=0.01$; Fig. $4 H)$. However, the fourth ventricle choroid plexus comparison did reveal a decrease in $\beta 2 \mathrm{nAChR}$ mRNA with nicotine self-administration (two-sided, unpaired $t$ test, $t_{(14)}=2.52, p=0.0245, R^{2}=0.31$; Fig. $4 F$ ).

\section{Nicotine self-administration selectively increases the mRNA expression of the choroid plexus-specific protein, transthyretin, in the $\mathrm{d} 3 \mathrm{~V}$}

To investigate whether nicotine differentially acts on the choroid plexus in a site-specific manner, we examined expression of the choroid plexus-specific protein, transthyretin, in rats self-administering saline or nicotine (for nicotine self-administration data, see Fig. 5). A prior study found that nicotine exposure increases transthyretin mRNA in gross dissections of the hippocampus and surrounding ventricles, as well as the protein in the CSF ( $\mathrm{Li}$ et al., 2000), but these investigations did not specifically isolate the choroid plexus tissue or examine expression across the choroid plexus ventricular sites. Further, since transthyretin protein is released from the choroid plexus and into the CSF in a dynamic manner, we focused on expression of the mRNA transcript 30-min following the end of the self-administration session with discrete dissections from each of the ventricular locations. Interestingly, a statistically significant increase was found in transthyretin mRNA expression with nicotine self-administration in the $\mathrm{d} 3 \mathrm{~V}$, which is localized in proximity to the medial habenula. Further, this increased expression was prevented with pretreatment of mecamylamine (2 $\mathrm{mg} / \mathrm{kg}$; one-way ANOVA, $F_{(2,13)}=11.31, p=0.0014, R^{2}=$ 0.6351 ; Fig. 6C). No differences in expression were found in the lateral ventricle (two-sided, unpaired $t$ test, $t_{(14)}=$ $0.14, p=0.8879, R^{2}=0.001$; Fig. $6 A$ ) or fourth ventricle (two-sided, unpaired $t$ test, $t_{(18)}=0.15, p=0.8804, R^{2}=$ 0.001 ; Fig. $6 B$ ) choroid plexus tissues, identifying regionspecific effects of nicotine's actions on this mechanism.

\section{Differential expression of mir-204 in the d3V choroid plexus with nicotine}

Given that miRNAs may be involved in the choroid plexus as an alternate mechanism of mediating cellular function, we next examined whether intravenous nicotine self-administration alters miRNA expression in the choroid plexus (for nicotine self-administration data, see Fig. 5). Specifically, mir-204 is localized to the sixth intron of the transient receptor potential melastatin 3 (TRPM3 gene) and is expressed under the control of this gene promotor in high density in the choroid plexus (Oberwinkler et al., 2005; Li et al., 2016). In a preliminary mir-204 gene expression assay ( $n=3$ /group), we found that nicotine self-administration induced a significant increase in mir-204 expression in the d3V choroid plexus (twosided, unpaired $t$ test, $t_{(4)}=3.98, p=0.0164, R^{2}=0.798$; mean \pm SEM: Saline: $10.82 \pm 5.19$ and Nicotine: $37.53 \pm$ 4.25; $* p<0.05)$ as compared to saline. However, group differences were not found in the lateral ventricle (twosided, unpaired $t$ test, $t_{(4)}=0.797, p=0.4699, R^{2}=$ 0.137; mean \pm SEM: Saline: $36.68 \pm 11.80$ and Nicotine: $52.97 \pm 16.66$ ) or fourth ventricle (two-sided, unpaired $t$ test, $t_{(4)}=0.185, p=0.8624, R^{2}=0.009$; mean \pm SEM: 

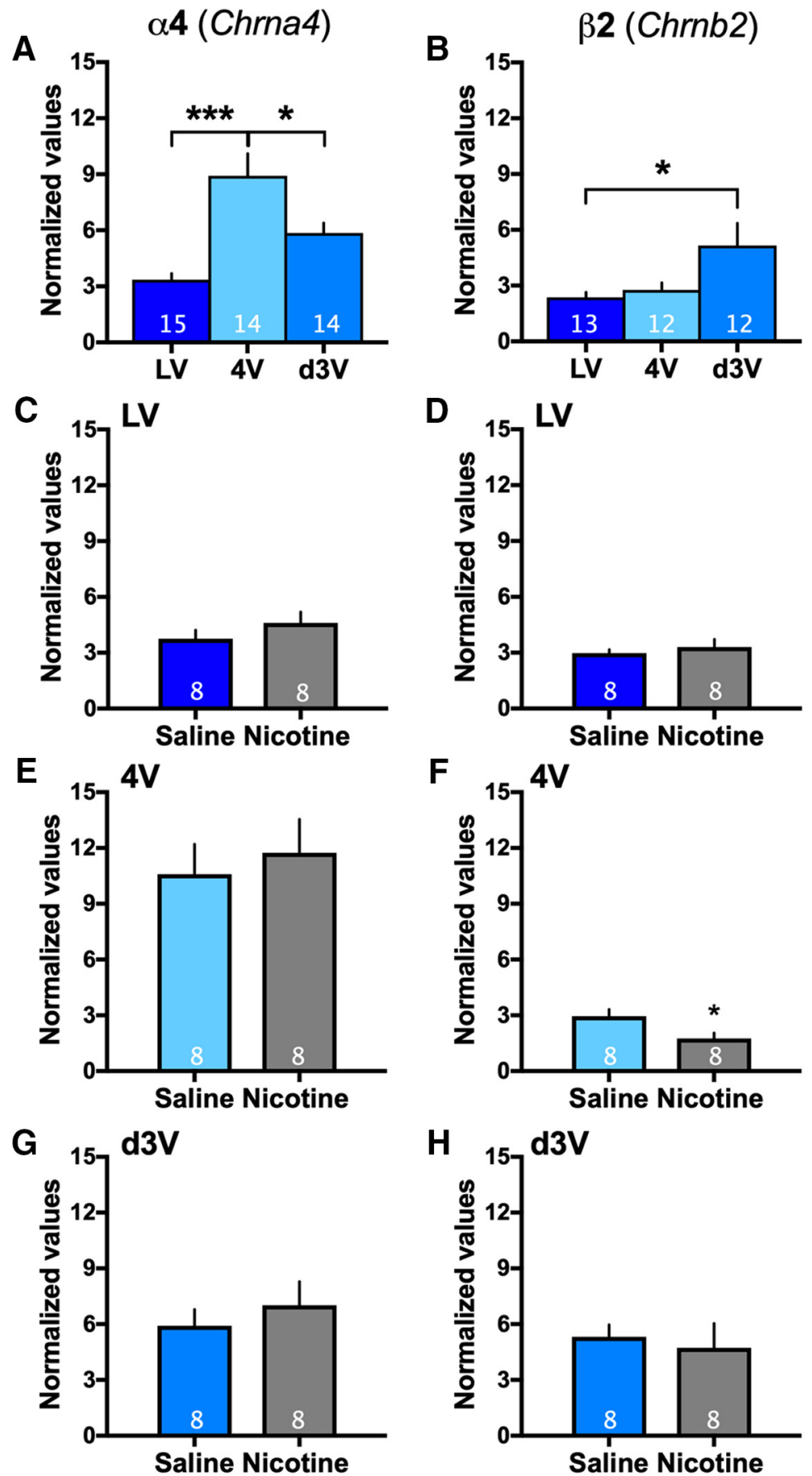

Figure 4. Differential expression of $\alpha 4$ and $\beta 2 \mathrm{nAChR}$ subunits across choroid plexus sites. $\boldsymbol{A}, \boldsymbol{B}$, Given that $\alpha 4$ and $\beta 2$ subunits were found in all choroid plexus sites, their relative expression was compared under baseline conditions $(n=12-15 / g r o u p$, specific number per group denoted on each bar). $\boldsymbol{A}$, For the $\alpha 4 \mathrm{nAChR}$ subunit, significantly increased expression was found in choroid plexus from the fourth ventricle compared to tissue from the lateral and d3V. Post hoc corrected for multiple comparisons; $* p<0.05, * * * p<$ 0.001 . Central tendency (mean) and variation (SEM) values for each are as follows: $L V: 3.350 \pm 0.34 ; 4 V: 8.925 \pm 1.18$; and d3V: 5.861 \pm 0.53. For each $\mathrm{nAChR}$ gene, expression data were normalized to expression of $\beta$-actin. $\boldsymbol{B}$, With regard to the $\beta 2 \mathrm{nAChR}$ subunit, significantly increased expression was found in the d3V choroid plexus as compared to the lateral ventricle (LV). Post hoc corrected for multiple comparisons; $* p<0.05$. Central tendency (mean) and variation (SEM) values for each are as follows: $L V: 2.371 \pm 0.27$; $4 \mathrm{~V}: 2.773 \pm 0.38$; and $d 3 \mathrm{~V}: 5.156 \pm 1.19) .4 \mathrm{~V}$ : fourth ventricle. For each nAChR gene, expression data were normalized to expression of $\beta$-actin. Data represent mean normalized values \pm SEM. $\boldsymbol{C}-\boldsymbol{H}$, Expression of $\alpha 4$ and $\beta 2 \mathrm{nAChR}$ subunits with nicotine or saline self-administration ( $n=8$ /group as denoted on each bar). Following saline or nicotine self-administration in rats, normalized expression levels of $\alpha 4$ and $\beta 2 \mathrm{nAChR}$ subunits were compared. For the $\alpha 4 \mathrm{nAChR}$ subunit (left panels), similar mRNA expression levels were found with saline and nicotine self-administration in choroid plexus from the $(\boldsymbol{C}) \mathrm{LV},(\boldsymbol{E}) 4 \mathrm{~V}$, and $(\boldsymbol{G}) \mathrm{d} 3 \mathrm{~V}$. For the $\beta 2 \mathrm{nAChR}$ subunit (right panels), differences were not found in mRNA expression in the $(\boldsymbol{D})$ LV or $(\boldsymbol{H})$ d3V, whereas a significant decrease with 
continued

nicotine was found in the $(\boldsymbol{F}) 4 \mathrm{~V}$ choroid plexus; $* p<0.05$. Central tendency (mean) and variation $(\mathrm{SEM})$ values $(\boldsymbol{C}-\boldsymbol{H})$ are as follows: $\alpha 4$ LV - Saline: $3.758 \pm 0.46$; Nicotine: $4.600 \pm 0.60 ; \alpha 44 \mathrm{~V}$ - Saline: $10.60 \pm 1.60 ;$ Nicotine: $11.74 \pm 1.79 ; \alpha 4$ d3V - Saline: 5.915 \pm 0.87; Nicotine: $7.015 \pm 1.28 ; \beta 2$ LV - Saline: $2.978 \pm 0.19 ;$ Nicotine: $3.310 \pm 0.41 ; \beta 24 V$ - Saline: $2.953 \pm 0.37 ;$ Nicotine: 1.762 $\pm 0.30 ; \beta 2 \mathrm{~d} 3 \mathrm{~V}$ - Saline: $5.319 \pm 0.66$; and Nicotine: $4.732 \pm 1.31$. For each nAChR gene, expression data were normalized to expression of $\beta$-actin. Data represent mean normalized values \pm SEM.

Saline: $53.16 \pm 7.31$ and Nicotine: $56.62 \pm 17.23)$. While the gene expression assay normalizes to the common housekeeping gene, $\beta$-actin, it may also identify other sections of the TRPM3 gene, in addition to mir-204. Therefore, we next used the more selective mir-204 microRNA assay that normalizes to U6, the preferred normalization factor for miRNA analysis in the field, to specifically validate the differences found with the gene assay. In the d3V choroid plexus, a significant increase in mir-204 expression was again evidenced with nicotine self-administration (two-sided, unpaired $t$ test, $t_{(11)}$ $=2.70, p=0.0103, R^{2}=0.399$; Fig. $7 C$ ), thus confirming the prior findings. Differences in mir-204 expression were not found between groups in the choroid plexus of the lateral ventricle (two-sided, unpaired $t$ test, $t_{(16)}=$ $0.60, p=0.555, R^{2}=0.022$ ) or fourth ventricle (twosided, unpaired $t$ test, $t_{(8)}=2.02, p=0.078, R^{2}=$ 0.339 ).

\section{Human choroid plexus expresses nAChRs, transthyretin and mir-204}

Since nAChR subtype distribution can vary across species (Gotti et al., 1997), we next validated the expression of $\mathrm{nAChR}$ subunit mRNA in tissue from humans. Expression of $\alpha 4, \alpha 7, \beta 2$ and $\beta 3 \mathrm{nAChR}$ subunits were identified, with $\alpha 4, \alpha 7$ and $\beta 3$ localized to the lateral ventricle (Fig. $8 A$ ) and $\alpha 4, \alpha 7$, and $\beta 2$ localized to the 3V (Fig. 8B). Expression of transthyretin (Fig. $8 C$ ) and mir-204 (Fig. 8D) were also found in both the lateral and $3 \mathrm{~V}$ human choroid plexus tissues.

\section{Discussion}

Together, the current studies reveal that activation of nicotinic receptors during nicotine self-administration induces an upregulation in transthyretin specifically within the $\mathrm{d} 3 \mathrm{~V}$ choroid plexus. This effect was reversed by the nicotinic receptor antagonist, mecamylamine, demon-
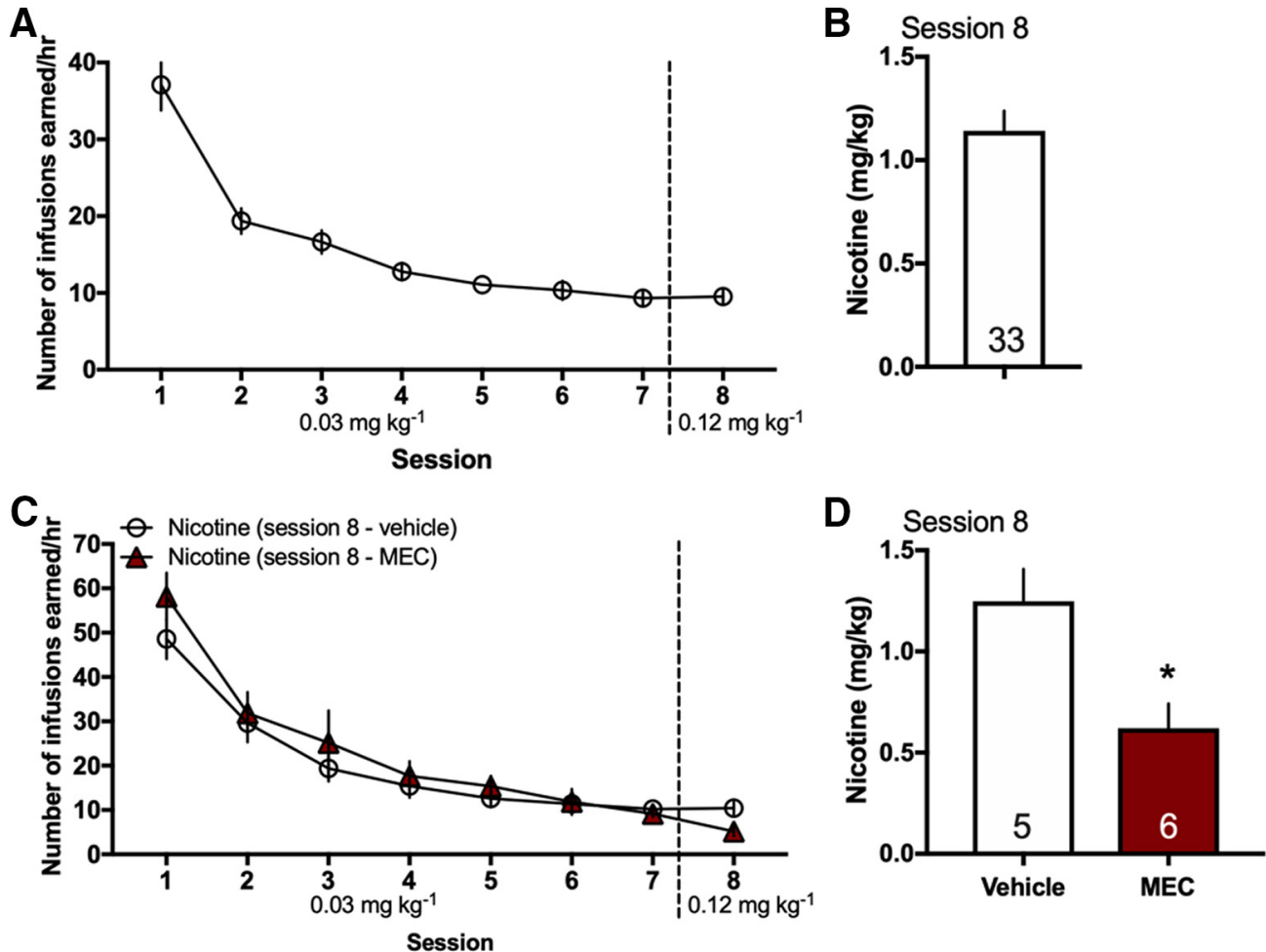

Figure 5. Intravenous nicotine self-administration in rats. Rats were trained in the intravenous nicotine self-administration protocol; access to the acquisition dose of $0.03 \mathrm{mg} \mathrm{kg}^{-1}$ per infusion was provided for $7 \mathrm{~d}$, followed by $0.12 \mathrm{mg} \mathrm{kg}^{-1}$ per infusion on the eighth session. $\boldsymbol{A}$, The number of nicotine infusions across sessions during nicotine self-administration corresponds to tissue analyzed for studies shown in Figures 4, 6, $7(n=33)$. $\boldsymbol{B}$, On the final session, the subjects shown in Figure $5 A$ self-administered a mean of 1.1 $\mathrm{mg} / \mathrm{kg}$ nicotine $( \pm 0.09 \mathrm{SEM})$. C , For the data presented in Figure $6 C$, groups were tested across doses as described above but were administered either vehicle or mecamylamine before the self-administration session on session 8 ( $n=5-6 / g r o u p)$. $\boldsymbol{D}$, For session 8 , a significant decrease in the amount of nicotine consumed was found in the mecamylamine group compared to the vehicle group; $* p<0.05$. The mean nicotine intake $(\mathrm{mg} / \mathrm{kg}) \pm$ SEM for each group was: Vehicle: $1.248 \pm 0.16$ and Mecamylamine: $0.62 \pm 0.122$. Specific subject numbers per group are denoted on the bar graphs. Data represent mean values \pm SEM. 

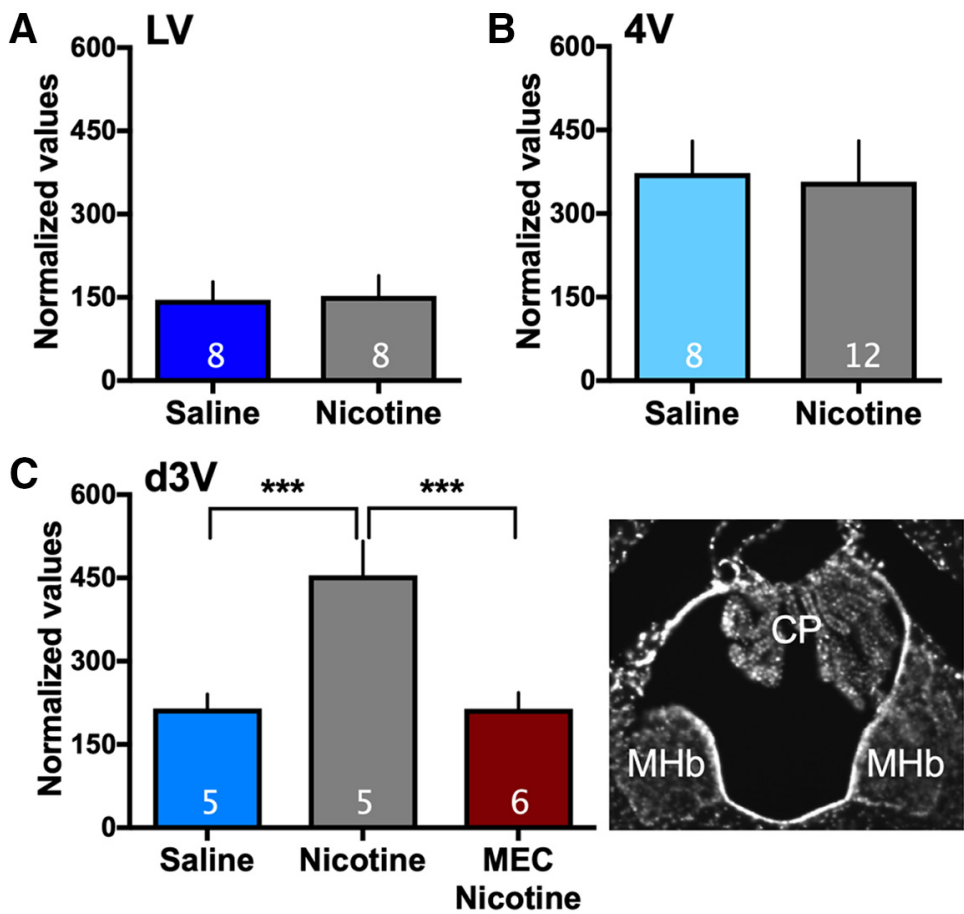

Figure 6. Transthyretin expression in the choroid plexus with saline or nicotine self-administration. Expression of choroid plexus specific transthyretin mRNA was examined in rats self-administering saline or nicotine $(n=5-12 /$ group, specific number per group denoted on each bar). $\boldsymbol{A}$, In the lateral ventricle (LV), differences were not found between groups in transthyretin expression. $\boldsymbol{B}$, In the fourth ventricle $(4 \mathrm{~V})$, no differences were found in transthyretin expression. $\mathbf{C}$, In the dorsal third ventricle (d3V), significant upregulation of transthyretin was found with nicotine self-administration, an effect that was reversed with pretreatment of mecamylamine (MEC) before nicotine self-administration; $* * * p<0.001$. The photomicrograph on the right displays the localization of the choroid plexus (CP) in the d3V, which is in proximity to the habenula ( $\mathrm{Hb})$. Central tendency (mean) and variation (SEM) values for each are as follows: $L V$ - Saline: $145.9 \pm 32.23$; Nicotine: $152.9 \pm 36.57 ; 4 V$ - Saline: $372.8 \pm 57.27$; Nicotine: $357.3 \pm 73.58$; d3V - Saline: $214.5 \pm 25.81$; Nicotine: $455.0 \pm 61.43$; and Mecamylamine/Nicotine: $214.3 \pm 29.21$. For all of the above, expression data were normalized to expression of $\beta$-actin. Data represent mean normalized values \pm SEM.

strating a direct effect of nicotine on the nAChRs in mediating gene expression. In addition to changes in transthyretin expression, nicotine also site specifically increased the expression of mir-204, a miRNA transcript found in high abundance within the choroid plexus. These effects on the choroid plexus could be attributed to en- dogenous cholinergic signaling mechanisms within the choroid plexus. Specifically, a subset of epithelial cells was found to express the cholinergic marker ChAT, and nAChR subunits were identified in all of the choroid plexus ventricular sites. Of further note, the specific nAChR subunit expression varied across ventricular regions, provid-
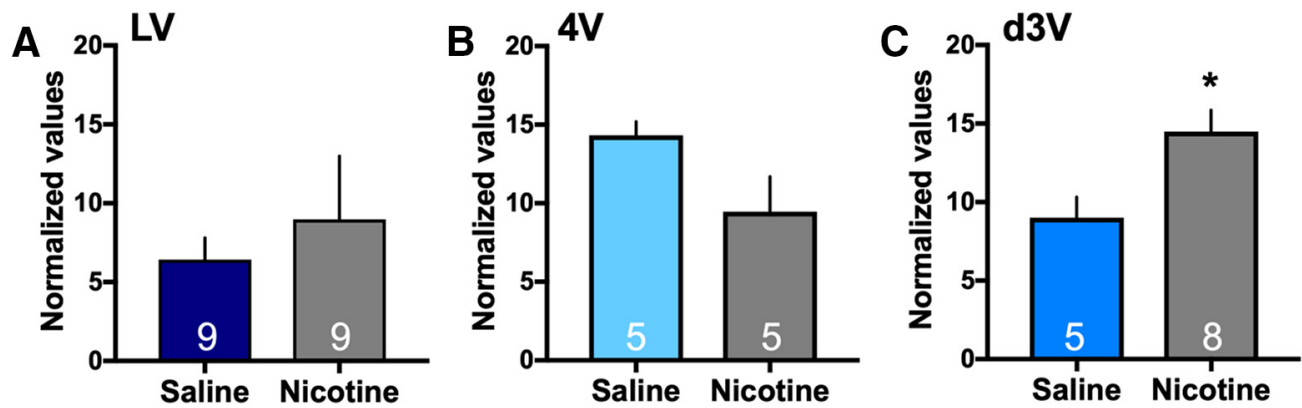

Figure 7. Nicotine mediated changes in expression of mir-204 in the choroid plexus. The expression of mir-204 was examined following saline or nicotine self-administration for each of the choroid plexus sites ( $n=5-9 / g r o u p$, specific number per group denoted on each bar). $\boldsymbol{A}$, Differences in expression of mir-204 were not found in the lateral ventricle choroid plexus between the nicotine and saline selfadministration groups. Central tendency (mean) and variation (SEM) values for each are as follows: Saline: $6.43 \pm 1.38$ and Nicotine: 8.98 \pm 4.01. B, In the fourth ventricle choroid plexus, statistically significant group differences were not found. Central tendency and variation: Saline: $14.32 \pm 0.87$ and Nicotine: $9.46 \pm 2.24$. $C$, In the d3V choroid plexus, nicotine self-administration induced a significant increase in the expression of mir-204 as compared to saline control. Central tendency (mean) and variation (SEM) values for each are as follows: Saline: $9.004 \pm 1.32$ and Nicotine: $14.49 \pm 1.36 ; * p<0.05$. Data represent mean normalized values \pm SEM 


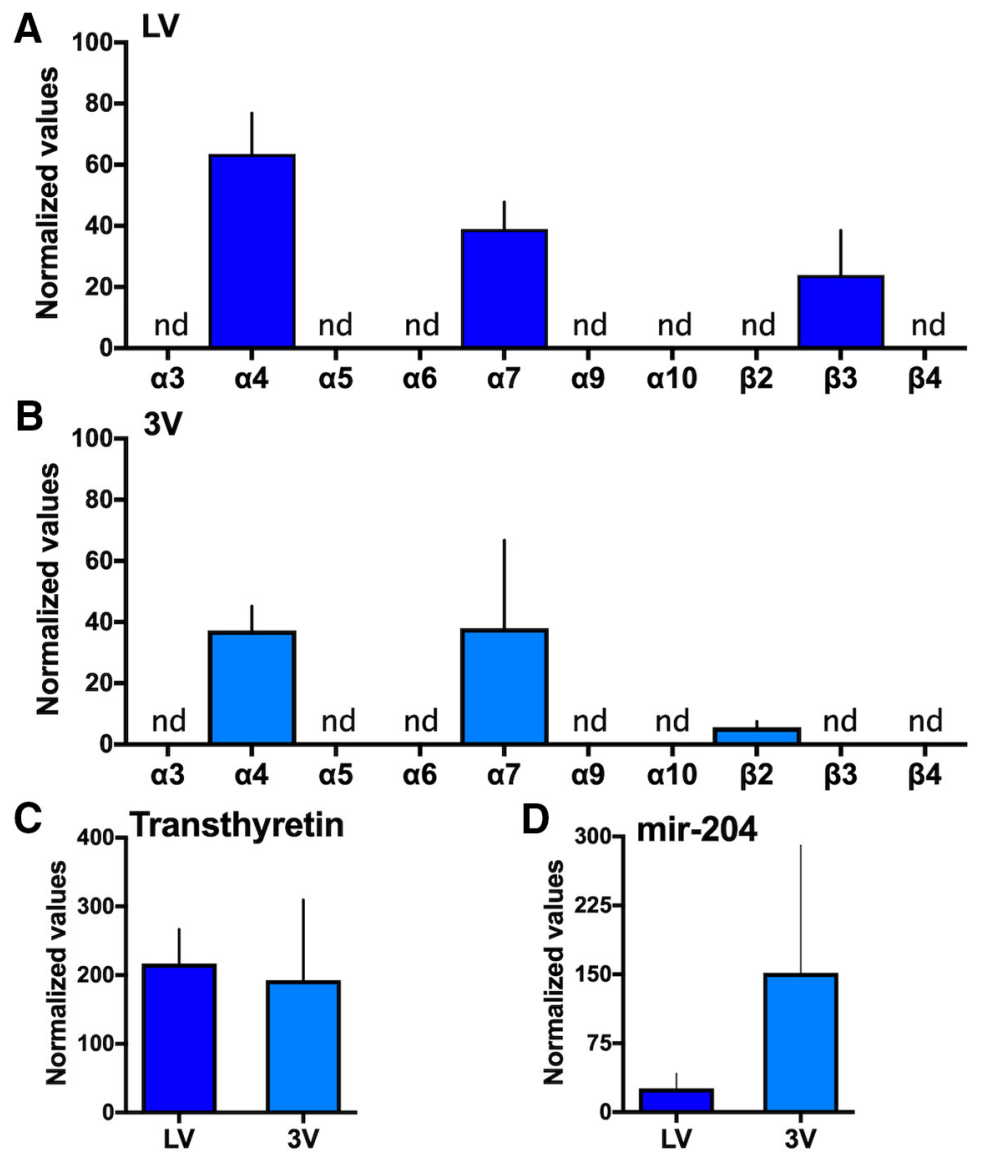

Figure 8. Expression of nAChR subunits, transthyretin and mir-204 in human choroid plexus tissue. Choroid plexus from the lateral and third ventricle (3V) were examined from postmortem humans ( $n=3$ for all analyses shown). $\boldsymbol{A}$, In the lateral ventricle (LV), mRNA expressions of $\alpha 4$ (CHRNA4), $\alpha 7$ (CHRNA7), and $\beta 3$ (CHRNB3) were detected. Statistical data are as follows Central tendency (mean) \pm variation (SEM), lower 95\% confidence interval, upper 95\% confidence interval: $\alpha 4: 63.51 \pm 13.39,5.88,121.1 ; \alpha 7: 38.97 \pm 8.83$, 0.95, 76.98; and $\beta 3: 23.97 \pm 14.55,0,86.56 . \mathbf{B}$, In the 3V, mRNA expressions of $\alpha 4$ (CHRNA4), $\alpha 7$ (CHRNA7), and $\beta 2$ (CHRNB2) were identified. Statistical data are: $\alpha 4: 37.30 \pm 7.90,3.33,71.28 ; \alpha 7: 38.06 \pm 28.76,0,161.8 ;$ and $\beta 2: 5.62 \pm 1.92,0,13.86$. C, Transthyretin expression was found at similar levels in the lateral and 3V of human tissue. Statistical data (mean \pm SEM, lower Cl, upper $\mathrm{Cl}$ ) are: $L V: 216.7 \pm 50.10,1.15,432.3$ and $3 V: 192.6 \pm 117.2,0,696.8$. D. Expression of mir-204 was abundantly localized in the $3 \mathrm{~V}$ choroid plexus, with lower levels found in the lateral ventricle tissue. Statistical data (mean $\pm \mathrm{SEM}$, lower $\mathrm{Cl}$, upper $\mathrm{Cl}$ ) are: $L V: 25.91 \pm 16.36,0,96.31$ and $3 V: 151.5 \pm 139.1,0,749.9$. Expression data were normalized to expression of $\beta$-actin $(n=3$ for each gene/region). For all of the above, the absence of a bar above the denoted nAChR subunit indicates that the mRNA was not detected (nd) based on the predetermined RT-qPCR criteria (Ct value $>35$ ). Data represent mean normalized values \pm SEM.

ing further evidence of the ability of nicotine to exert site-specific effects on choroid plexus mechanisms. The nAChRs were also shown to be functionally active as nicotine directly led to increased cellular excitability, as evidenced with $\mathrm{Ca}^{2+}$ influx. Finally, cholinergic signaling mechanisms were also discovered in human choroid plexus, supporting the translational relevance of the current studies. Taken together, these findings expand our understanding of the extent of cholinergic function in the brain and elucidate a previously unrecognized source of signaling that may be alternately regulated under states of cholinergic dysfunction and/or with pharmacological activation of $\mathrm{nAChRs}$, such as during nicotine dependence.

\section{Site-specific differences in the choroid plexus}

While prior characterization of the choroid plexus has assumed similar function across ventricular sites, recent findings in embryonic mice have suggested differential transcript expression during development (Lun et al., 2015b). The current findings provide novel evidence of region-specific function of the choroid plexus during adulthood, as nicotine self-administration induced differences in gene and miRNA expression selectively in the $\mathrm{d} 3 \mathrm{~V}$. The reason for such different actions of nicotine may be attributed to the nAChR subtype expressed within the discrete tissue locations. In the d3V, the $\alpha 4, \alpha 7, \beta 2$, and $\beta 3 \mathrm{nAChR}$ subtypes were found in the choroid plexus, consistent with expression patterns exhibited in this region in nAChR subunit transgenic mice (GENSAT, 2019). The $\alpha 4$ and $\beta 2$ subunits can combine together to form a functional receptor subtype, and the $\beta 3$ subunit has been shown to co-assemble with the $\alpha 4 \beta 2$ subtype as well. In contrast, the $\alpha 7$ subunit most often forms a homomeric structure, although some reports suggest the presence of an $\alpha 7 \beta 2$ functional subtype (Wu et al., 2016). Moreover, the $\alpha 4 \beta 2$ and $\alpha 7 \mathrm{nAChR}$ subtypes demonstrate functional 
differences with ligand binding. The $\alpha 4 \beta 2$-containing nAChR subtype has a high probability of opening and slower desensitization rate (Li and Steinbach, 2010), whereas the $\alpha 7 \mathrm{nAChR}$ subtype exhibits higher calcium permeability, lower probability of opening, and rapid desensitization (Williams et al., 2011). Notably, the $\alpha 4 \beta 2$ and $\alpha 7$ receptor subtypes have been implicated in learning and memory, drug reinforcement, anxiety, schizophrenia, and immune function (Fowler et al., 2008; Dani, 2015; Wu et al., 2016). The latter function provides an important consideration given that the choroid plexus modulates innate immunity and viral infiltration into the brain (Skok et al., 2005; Vercellino et al., 2008; Ridder et al., 2014; Zhang et al., 2015; Wu et al., 2016). In our $\mathrm{Ca}^{2+}$ imaging study, we provide further evidence that functional nAChRs are present in choroid plexus epithelial cells, as nicotine exposure resulted in substantial intracellular $\mathrm{Ca}^{2+}$ influx. These studies also documented a subpopulation of cells exhibiting excitability with nicotine application, which parallels the relative proportion of cholinergic epithelial cells found in the choroid plexus in the fluorescence reporter mice. Moreover, the temporal evolution of the $\mathrm{Ca}^{2+}$ responses in vitro closely mimics the temporal patterns of $\mathrm{Ca}^{2+}$ fluxes found with $\alpha 4 \beta 2$ nAChRs in different preparations (Vernino et al., 1994; Demuro et al., 2001).

Of further note, we did not detect any significant differences in nAChR subunit mRNA expression with intravenous nicotine self-administration, with the exception of a decrease in $\beta 2$ subunit expression in the fourth ventricle. In prior studies (Marks et al., 1992; Pauly et al., 1996), $\mathrm{nAChR}$ binding has been shown to increase at the cellular membrane during chronic nicotine administration via implanted minipump, whereas limited differences in mRNA expression were evidenced. Since nicotine has been shown to act as a 'molecular chaperone' to facilitate the trafficking and insertion of $\alpha 4$-containing and $\beta 2$ containing nAChR subtypes into the cell membrane (Kuryatov et al., 2005; Srinivasan et al., 2011; Henderson et al., 2014), it is possible that altered expression of nAChRs on the cell membrane could have been induced under the self-administration conditions, an intriguing possibility that will need to be examined in further studies.

\section{Potential relevance to human disease}

The specific effect of nicotine on transthyretin expression within the d3V has several implications. After being released from the choroid plexus into the CSF, transthyretin transports thyroxine and retinol/retinol binding protein throughout the brain. Interestingly, differences in transthyretin levels have been noted in clinical populations. For instance, patients with schizophrenia have been found to have reduced levels of transthyretin and altered nicotinic receptor signaling has been associated with schizophrenia in humans and animal models (Diwan et al., 1998; Wan et al., 2006; Koukouli et al., 2017), suggesting a potential relevance of choroid plexus function in the disease state. With regard to Alzheimer's disease and dementia, a decrease in transthyretin is correlated with increased risk of severe dementia (Serot et al., 1997).
Transthyretin has been proposed to prevent $A \beta$ fibrillogenesis to limit disease progression (Schwarzman et al., 1994; Golabek et al., 1995). Increased nicotine consumption in smokers has also been correlated with decreased risk of Alzheimer's disease (van Duijn and Hofman, 1991), and in mice, nicotine treatment reduces the presence of insoluble A $\beta$ (Nordberg et al., 2002; Inestrosa et al., 2013). Although prior findings appeared to support the hypothesis that nicotine may act through transthyretin to beneficially modify Alzheimer's disease pathology ( $L i$ et al., 2000), findings from the current study suggest that any beneficial effects of transthyretin would be limited to regions in close proximity to the d3V. Further, it is worthwhile to note that in our analysis of the human tissue, variability was noted in the levels of transcript expression, which could potentially be attributed to individual differences among the subjects (e.g., sex; ethnic background; history of drug use: tobacco, psychostimulants, or alcohol). Moreover, reduced levels of mir-204 have been found in the CSF of patients with frontotemporal dementia (FTD), and as such, this miRNA has been proposed to be a biomarker for the disease state (Nissen et al., 2018). In light of the current findings, such a proposed biomarker approach will need to consider smoking status since nicotine may mitigate the level of mir-204 expression. Further, it will be important in future studies to more directly determine whether mir-204 alters gene expression underlying pathology affecting memory function and whether nicotine could modulate any changes in this regard.

\section{Conclusions}

The current studies identify a previously unrecognized source of cholinergic signaling within the brain and identify the direct mechanism through which nicotine acts on this tissue to alter function. Findings derived from the human choroid plexus further support the translational relevance of the rodent studies. In addition to important implications for tobacco/nicotine dependence, the current findings elucidate a mechanism through which cholinergic signaling may impact global brain function via release of factors into the CSF, which could further our understanding of multiple disease states characterized by cholinergic dysfunction, and these findings may also have important implications for patients prescribed pharmacotherapeutics with actions on the cholinergic system.

\section{References}

Balusu S, Van Wonterghem E, De Rycke R, Raemdonck K, Stremersch S, Gevaert K, Brkic M, Demeestere D, Vanhooren V, Hendrix A, Libert C, Vandenbroucke RE (2016) Identification of a novel mechanism of blood-brain communication during peripheral inflammation via choroid plexus-derived extracellular vesicles. EMBO Mol Med 8:1162-1183.

Bateman RJ, Munsell LY, Morris JC, Swarm R, Yarasheski KE, Holtzman DM (2006) Human amyloid-beta synthesis and clearance rates as measured in cerebrospinal fluid in vivo. Nat Med 12:856-861.

Benwell ME, Balfour DJ, Anderson JM (1988) Evidence that tobacco smoking increases the density of $(-)-[3 \mathrm{H}]$ nicotine binding sites in human brain. J Neurochem 50:1243-1247. 
Bohnen NI, Albin RL (2011) The cholinergic system and Parkinson disease. Behav Brain Res 221:564-573.

Bordia T, Grady SR, McIntosh JM, Quik M (2007) Nigrostriatal damage preferentially decreases a subpopulation of alpha6beta2* nAChRs in mouse, monkey, and Parkinson's disease striatum. Mol Pharmacol 72:52-61.

Breese CR, Marks MJ, Logel J, Adams CE, Sullivan B, Collins AC, Leonard S (1997) Effect of smoking history on [3H]nicotine binding in human postmortem brain. J Pharmacol Exp Ther 282:7-13.

Chen E, Lallai V, Sherafat Y, Grimes NP, Pushkin AN, Fowler JP, Fowler CD (2018) Altered baseline and nicotine-mediated behavioral and cholinergic profiles in ChAT-Cre mouse lines. J Neurosci 38:2177-2188.

Coyle JT, Price DL, DeLong MR (1983) Alzheimer's disease: a disorder of cortical cholinergic innervation. Science 219:1184-1190.

Dani JA (2015) Neuronal nicotinic acetylcholine receptor structure and function and response to nicotine. Int Rev Neurobiol 124:3-19.

Dani JA, Jenson D, Broussard JI, De Biasi M (2011) Neurophysiology of nicotine addiction. J Addict Res Ther S1 pii: 001.

Demuro A, Parker I (2005) "Optical patch-clamping": single-channel recording by imaging $\mathrm{Ca} 2+$ flux through individual muscle acetylcholine receptor channels. J Gen Physiol 126:179-192.

Demuro A, Parker I (2006) Imaging single-channel calcium microdomains. Cell Calcium 40:413-422.

Demuro A, Palma E, Eusebi F, Miledi R (2001) Inhibition of nicotinic acetylcholine receptors by bicuculline. Neuropharmacology 41 : 854-861.

Derkow K, Rössling R, Schipke C, Krüger C, Bauer J, Fähling M, Stroux A, Schott E, Ruprecht K, Peters O, Lehnardt S (2018) Distinct expression of the neurotoxic microRNA family let-7 in the cerebrospinal fluid of patients with Alzheimer's disease. PLoS One 13:e0200602.

Diwan A, Castine M, Pomerleau CS, Meador-Woodruff JH, Dalack GW (1998) Differential prevalence of cigarette smoking in patients with schizophrenic vs mood disorders. Schizophr Res 33:113-118.

Fowler CD, Kenny PJ (2014) Nicotine aversion: neurobiological mechanisms and relevance to tobacco dependence vulnerability. Neuropharmacology 76 [Pt B]:533-544.

Fowler CD, Arends MA, Kenny PJ (2008) Subtypes of nicotinic acetylcholine receptors in nicotine reward, dependence, and withdrawal: evidence from genetically modified mice. Behav Pharmacol 19:461-484.

Fowler CD, Lu Q, Johnson PM, Marks MJ, Kenny PJ (2011) Habenular $\alpha 5$ nicotinic receptor subunit signalling controls nicotine intake. Nature 471:597-601.

Frahm S, Slimak MA, Ferrarese L, Santos-Torres J, Antolin-Fontes B, Auer S, Filkin S, Pons S, Fontaine JF, Tsetlin V, Maskos U, Ibañez-Tallon I (2011) Aversion to nicotine is regulated by the balanced activity of $\beta 4$ and $\alpha 5$ nicotinic receptor subunits in the medial habenula. Neuron 70:522-535.

GENSAT (2019) The gene expression nervous system atlas (GENSAT) project. New York, NY: The Rockefeller University. Available at www.gensat.org.

Golabek A, Marques MA, Lalowski M, Wisniewski T (1995) Amyloid beta binding proteins in vitro and in normal human cerebrospinal fluid. Neurosci Lett 191:79-82.

Gotti C, Moretti M, Maggi R, Longhi R, Hanke W, Klinke N, Clementi F (1997) Alpha7 and alpha8 nicotinic receptor subtypes immunopurified from chick retina have different immunological, pharmacological and functional properties. Eur J Neurosci 9:1201-1211.

Grady SR, Meinerz NM, Cao J, Reynolds AM, Picciotto MR, Changeux JP, Mclntosh JM, Marks MJ, Collins AC (2001) Nicotinic agonists stimulate acetylcholine release from mouse interpeduncular nucleus: a function mediated by a different nAChR than dopamine release from striatum. J Neurochem 76:258-268.

Gray R, Rajan AS, Radcliffe KA, Yakehiro M, Dani JA (1996) Hippocampal synaptic transmission enhanced by low concentrations of nicotine. Nature 383:713-716.

Henderson BJ, Srinivasan R, Nichols WA, Dilworth CN, Gutierrez DF, Mackey ED, McKinney S, Drenan RM, Richards Cl, Lester HA
(2014) Nicotine exploits a COPI-mediated process for chaperonemediated up-regulation of its receptors. J Gen Physiol 143:51-66. Inestrosa NC, Godoy JA, Vargas JY, Arrazola MS, Rios JA, Carvajal FJ, Serrano FG, Farias GG (2013) Nicotine prevents synaptic impairment induced by amyloid- $\beta$ oligomers through $\alpha 7$-nicotinic acetylcholine receptor activation. Neuromolecular Med 15:549569.

Johanson CE, Duncan JA, Stopa EG, Baird A (2005) Enhanced prospects for drug delivery and brain targeting by the choroid plexus-CSF route. Pharm Res 22:1011-1037.

Jorenby DE, Hays JT, Rigotti NA, Azoulay S, Watsky EJ, Williams KE, Billing CB, Gong J, Reeves KR (2006) Efficacy of varenicline, an alpha4beta2 nicotinic acetylcholine receptor partial agonist, vs placebo or sustained-release bupropion for smoking cessation: a randomized controlled trial. JAMA 296:56-63.

Koukouli F, Rooy M, Tziotis D, Sailor KA, O'Neill HC, Levenga J, Witte M, Nilges M, Changeux JP, Hoeffer CA, Stitzel JA, Gutkin BS, DiGregorio DA, Maskos U (2017) Nicotine reverses hypofrontality in animal models of addiction and schizophrenia. Nat Med 23:347-354.

Krzyzanowska A, Carro E (2012) Pathological alteration in the choroid plexus of Alzheimer's disease: implication for new therapy approaches. Front Pharmacol 3:75.

Kuryatov A, Luo J, Cooper J, Lindstrom J (2005) Nicotine acts as a pharmacological chaperone to up-regulate human alpha4beta2 acetylcholine receptors. Mol Pharmacol 68:1839-1851.

Lee WD, Wang KC, Tsai YF, Chou PC, Tsai LK, Chien CL (2016) Subarachnoid hemorrhage promotes proliferation, differentiation, and migration of neural stem cells via BDNF upregulation. PLoS One 11:e0165460.

Lehtinen MK, Walsh CA (2011) Neurogenesis at the braincerebrospinal fluid interface. Annu Rev Cell Dev Biol 27:653-679.

Lehtinen MK, Zappaterra MW, Chen X, Yang YJ, Hill AD, Lun M, Maynard T, Gonzalez D, Kim S, Ye P, D'Ercole AJ, Wong ET, LaMantia AS, Walsh CA (2011) The cerebrospinal fluid provides a proliferative niche for neural progenitor cells. Neuron 69:893-905.

Li MD, Kane JK, Matta SG, Blaner WS, Sharp BM (2000) Nicotine enhances the biosynthesis and secretion of transthyretin from the choroid plexus in rats: implications for beta-amyloid formation. $J$ Neurosci 20:1318-1323.

Li P, Steinbach JH (2010) The neuronal nicotinic alpha4beta2 receptor has a high maximal probability of being open. $\mathrm{Br} \mathrm{J}$ Pharmacol 160:1906-1915.

Li T, Pan H, Li R (2016) The dual regulatory role of miR-204 in cancer. Tumour Biol 37:11667-11677.

Lun MP, Monuki ES, Lehtinen MK (2015a) Development and functions of the choroid plexus-cerebrospinal fluid system. Nat Rev Neurosci 16:445-457.

Lun MP, Johnson MB, Broadbelt KG, Watanabe M, Kang YJ, Chau KF, Springel MW, Malesz A, Sousa AM, Pletikos M, Adelita T, Calicchio ML, Zhang Y, Holtzman MJ, Lidov HG, Sestan N, Steen $\mathrm{H}$, Monuki ES, Lehtinen MK (2015b) Spatially heterogeneous choroid plexus transcriptomes encode positional identity and contribute to regional CSF production. J Neurosci 35:4903-4916.

Marks MJ, Pauly JR, Gross SD, Deneris ES, Hermans-Borgmeyer I, Heinemann SF, Collins AC (1992) Nicotine binding and nicotinic receptor subunit RNA after chronic nicotine treatment. J Neurosci 12:2765-2784.

McHardy SF, Wang HL, McCowen SV, Valdez MC (2017) Recent advances in acetylcholinesterase inhibitors and reactivators: an update on the patent literature (2012-2015). Expert Opin Ther Pat 27:455-476.

Nissen NI, Anderson KR, Wang H, Lee HS, Garrison C, Eichelberger SA, Ackerman K, Im W, Miwa JM (2018) Augmenting the antinociceptive effects of nicotinic acetylcholine receptor activity through lynx1 modulation. PLoS One 13:e0199643.

Nordberg A, Hellström-Lindahl E, Lee M, Johnson M, Mousavi M, Hall R, Perry E, Bednar I, Court J (2002) Chronic nicotine treatment reduces beta-amyloidosis in the brain of a mouse model of Alzheimer's disease (APPsw). J Neurochem 81:655-658. 
Oberwinkler J, Lis A, Giehl KM, Flockerzi V, Philipp SE (2005) Alternative splicing switches the divalent cation selectivity of TRPM3 channels. J Biol Chem 280:22540-22548.

Ochoa V, Loeffler AJ, Fowler CD (2015) Emerging role of the cerebrospinal fluid - neuronal interface in neuropathology. Neuro 2:9298.

Parikh V, Kozak R, Martinez V, Sarter M (2007) Prefrontal acetylcholine release controls cue detection on multiple timescales. Neuron 56:141-154.

Pauly JR, Marks MJ, Robinson SF, van de Kamp JL, Collins AC (1996) Chronic nicotine and mecamylamine treatment increase brain nicotinic receptor binding without changing alpha 4 or beta 2 mRNA levels. J Pharmacol Exp Ther 278:361-369.

Picciotto MR, Zoli M, Rimondini R, Léna C, Marubio LM, Pich EM, Fuxe K, Changeux JP (1998) Acetylcholine receptors containing the beta2 subunit are involved in the reinforcing properties of nicotine. Nature 391:173-177.

Picciotto MR, Higley MJ, Mineur YS (2012) Acetylcholine as a neuromodulator: cholinergic signaling shapes nervous system function and behavior. Neuron 76:116-129.

Potter R, Patterson BW, Elbert DL, Ovod V, Kasten T, Sigurdson W, Mawuenyega K, Blazey T, Goate A, Chott R, Yarasheski KE, Holtzman DM, Morris JC, Benzinger TL, Bateman RJ (2013) Increased in vivo amyloid-beta42 production, exchange, and loss in presenilin mutation carriers. Sci Transl Med 5:189ra177.

Riancho J, Vázquez-Higuera JL, Pozueta A, Lage C, Kazimierczak M, Bravo M, Calero M, Gonalezález A, Rodríguez E, Lleó A, SánchezJuan P (2017) MicroRNA profile in patients with Alzheimer's disease: analysis of miR-9-5p and miR-598 in raw and exosome enriched cerebrospinal fluid samples. J Alzheimers Dis 57:483491.

Ridder K, Keller S, Dams M, Rupp AK, Schlaudraff J, Turco DD, Starmann J, Macas J, Karpova D, Devraj K, Depboylu C, Landfried $B$, Arnold B, Plate $\mathrm{KH}$, Höglinger $\mathrm{G}$, Sültmann $\mathrm{H}$, Altevogt $\mathrm{P}$, Momma S (2014) Extracellular vesicle-mediated transfer of genetic information between the hematopoietic system and the brain in response to inflammation. PLoS Biol 12:e1001874.

Sarter M, Lustig C, Taylor SF (2012) Cholinergic contributions to the cognitive symptoms of schizophrenia and the viability of cholinergic treatments. Neuropharmacology 62:1544-1553.

Schwarzman AL, Gregori L, Vitek MP, Lyubski S, Strittmatter WJ, Enghilde JJ, Bhasin R, Silverman J, Weisgraber KH, Coyle PK
(1994) Transthyretin sequesters amyloid beta protein and prevents amyloid formation. Proc Natl Acad Sci USA 91:8368-8372.

Serot JM, Christmann D, Dubost T, Couturier M (1997) Cerebrospinal fluid transthyretin: aging and late onset Alzheimer's disease. J Neurol Neurosurg Psychiatry 63:506-508.

Skok M, Grailhe R, Changeux JP (2005) Nicotinic receptors regulate B lymphocyte activation and immune response. Eur J Pharmacol 517:246-251.

Spector R, Goldberg MJ (1982) Active transport of nicotine by the isolated choroid plexus in vitro. J Neurochem 38:594-596.

Srinivasan R, Pantoja R, Moss FJ, Mackey ED, Son CD, Miwa J, Lester HA (2011) Nicotine up-regulates alpha4beta2 nicotinic receptors and ER exit sites via stoichiometry-dependent chaperoning. J Gen Physiol 137:59-79.

van Duijn CM, Hofman A (1991) Relation between nicotine intake and Alzheimer's disease. BMJ 302:1491-1494.

Vercellino M, Votta B, Condello C, Piacentino C, Romagnolo A, Merola A, Capello E, Mancardi GL, Mutani R, Giordana MT, Cavalla P (2008) Involvement of the choroid plexus in multiple sclerosis autoimmune inflammation: a neuropathological study. J Neuroimmunol 199:133-141.

Vernino S, Rogers M, Radcliffe KA, Dani JA (1994) Quantitative measurement of calcium flux through muscle and neuronal nicotinic acetylcholine receptors. J Neurosci 14:5514-5524.

Wan C, Yang Y, Li H, La Y, Zhu H, Jiang L, Chen Y, Feng G, He L (2006) Dysregulation of retinoid transporters expression in body fluids of schizophrenia patients. J Proteome Res 5:3213-3216.

Whitehouse PJ, Price DL, Struble RG, Clark AW, Coyle JT, Delon MR (1982) Alzheimer's disease and senile dementia: loss of neurons in the basal forebrain. Science 215:1237-1239.

Williams DK, Stokes C, Horenstein NA, Papke RL (2011) The effective opening of nicotinic acetylcholine receptors with single agonist binding sites. J Gen Physiol 137:369-384.

Wu J, Liu Q, Tang P, Mikkelsen JD, Shen J, Whiteaker P, Yakel JL (2016) Heteromeric $\alpha 7 \beta 2$ nicotinic acetylcholine receptors in the brain. Trends Pharmacol Sci 37:562-574.

Zhang B, Yu JY, Liu LQ, Peng L, Chi F, Wu CH, Jong A, Wang SF, Cao H, Huang SH (2015) Alpha7 nicotinic acetylcholine receptor is required for blood-brain barrier injury-related CNS disorders caused by Cryptococcus neoformans and HIV-1 associated comorbidity factors. BMC Infect Dis 15:352. 